\title{
Does marriage protect against hospitalization with pneumonia? A population-based case-control study
}

This article was published in the following Dove Press journal:

Clinical Epidemiology

10 October 2013

Number of times this article has been viewed

\section{Anil Mor \\ Sinna P Ulrichsen \\ Elisabeth Svensson \\ Klara Berencsi \\ Reimar W Thomsen}

Department of Clinical Epidemiology, Institute of Clinical Medicine, Aarhus University Hospital, Aarhus, Denmark
Correspondence: Anil Mor Department of Clinical Epidemiology, Aarhus University Hospital, Olof Palmes Allé 43-45, DK-8200 Aarhus N, Denmark $\mathrm{Tel}+4587168486$

Fax +45 87I6 7215

Email anil.mor@dce.au.dk
Background: To reduce the increasing burden of pneumonia hospitalizations, we need to understand their determinants. Being married may decrease the risk of severe infections, due to better social support and healthier lifestyle.

Patients and methods: In this population-based case-control study, we identified all adult patients with a first-time pneumonia-related hospitalization between 1994 and 2008 in Northern Denmark. For each case, ten sex- and age-matched population controls were selected from Denmark's Civil Registration System. We performed conditional logistic regression analysis to estimate the odds ratios (ORs) for pneumonia hospitalization among persons who were divorced, widowed, or never married, as compared with married persons, adjusting for age, sex, 19 different comorbidities, alcoholism-related conditions, immunosuppressant use, urbanization, and living with small children.

Results: The study included 67,162 patients with a pneumonia-related hospitalization and 671,620 matched population controls. Compared with controls, the pneumonia patients were more likely to be divorced (10\% versus $7 \%$ ) or never married (13\% versus $11 \%)$. Divorced and never-married patients were much more likely to have previous diagnoses of alcoholismrelated conditions (18\% and $11 \%$, respectively) compared with married (3\%) and widowed $(6 \%)$ patients. The adjusted OR for pneumonia-related hospitalization was increased, at 1.29 (95\% confidence interval [CI]: 1.25-1.33) among divorced; 1.15 (95\% CI: 1.12-1.17) among widowed; and 1.33 (95\% CI: 1.29-1.37) among never-married individuals as compared with those who were married.

Conclusion: Married individuals have a decreased risk of being hospitalized with pneumonia compared with never-married, divorced, and widowed patients.

Keywords: marital status, risk, mortality, immune function

\section{Introduction}

Hospitalizations with pneumonia have increased by up to $50 \%$ in western populations during the past 15 years, ${ }^{1-3}$ and pneumonia is one of the main causes of mortality for hospitalized patients. ${ }^{4-6}$ To reduce the burden of pneumonia hospitalizations, we need to understand the determinants that increase the risk of hospitalization with pneumonia.

Epidemiological studies suggest that marriage has a protective effect on hospitalization and mortality for a number of diseases ${ }^{7-12}$ in addition to higher social support, this association may be related to lower psychological distress, better immune function, a healthier lifestyle, and more positive health behaviours. ${ }^{7,9,11,13}$ Studies examining the association between marital status and risk of 
pneumonia are sparse. In a questionnaire-based case-control study including 563 patients (178 surviving pneumonia cases and 385 randomly selected controls from the same area), Farr et al found that individuals with single marital status had higher risk of hospitalization for pneumonia compared with individuals who were married (odds ratio [OR]: 1.74, 95\% confidence interval [CI]: 1.19-2.54). ${ }^{14}$ Farr et al raised the hypothesis that doctors were more likely to admit single patients compared with married individuals, due to single patients with pneumonia being less able to take care of themselves at home. Also, divorce or widowing may predict decreasing social support and increasingly negative health behaviors.

To our knowledge, no previous study has estimated the risk of incident pneumonia hospitalization among divorced, widowed, and never-married individuals. We thus undertook a large population-based case-control study to explore the association between marital status and risk of hospitalization for pneumonia.

\section{Material and methods}

We conducted this study in Northern Denmark, with a mixed rural and urban population of approximately 1.15 million inhabitants. The Danish National Health Service provides free health care for all residents, including free access to primary care and hospitals and reimbursement of a portion of the cost of most prescription drugs. ${ }^{15}$ The use of central personal registration numbers, unique identifiers assigned to each Danish citizen at birth or immigration, allowed for accurate linkage between all health care registries used in this study. ${ }^{16}$

\section{Identification of patients hospitalized with pneumonia}

The Danish National Registry of Patients (DNRP) contains information on all hospitalizations in Denmark that have occurred since 1977, and all outpatient and emergency room visits have also been included since $1995 .{ }^{17}$ The DNRP includes information on the patient's central personal registration number and the primary discharge diagnosis and up to 20 secondary discharge diagnoses, according to the International Classification of Diseases (ICD) (eighth edition until the end of 1993 and tenth edition thereafter).

We identified all hospitalized patients aged 15 years or older who had lived in Northern Denmark at least 12 months before admission and who had one of the following first-time primary (first listed) or secondary discharge diagnoses recorded between 1994 and 2008: viral or bacterial pneumonia (J12.x-J18.x), legionellosis (A481.x), or ornithosis (A709.x). ${ }^{3}$

\section{Selection of population controls}

The civil registration system (CRS) contains all electronic records of vital status (alive, date of death, or emigration); place of residence (address); and marital status, for the entire Danish population since 1968 and is updated daily. ${ }^{16}$ On the date of each patient's first (incident) pneumoniarelated hospital admission (the index date), we selected ten controls from the CRS, matched by year of birth, sex, and residence. We employed the risk set sampling technique, ${ }^{18}$ ie, the eligible controls had to be alive and at risk of a first hospitalization with pneumonia on the date the corresponding case was admitted.

\section{Data on marital status}

For both cases and controls, information on marital status was obtained from the CRS. The civil status on the index date was selected as the current marital status. We categorized the patients into four subcategories: (1) married; (2) never married; (3) divorced; and (4) widowed. A total of $179(0.3 \%)$ cases and $1374(0.2 \%)$ controls had unknown marital status and were omitted from further analyses.

\section{Data on potential confounders}

We obtained data on potential confounding factors from several registries, including the DNRP, the Aarhus University Prescription Database, ${ }^{19}$ and the CRS. To control for comorbidities that may be associated with pneumonia risk, we assessed for the presence of the 19 major disease categories included in the Charlson Comorbidity Index (CCI), for each pneumonia case and population control subject, based on the case and control subject's complete hospital contact history before the index date. ${ }^{20,21}$ The CCI includes major risk factors for pneumonia, such as chronic obstructive pulmonary disease (COPD), previous cardiovascular and cerebrovascular disease, heart failure, diabetes, cancer, and human immunodeficiency virus (HIV)/acquired immunodeficiency syndrome (AIDS). ${ }^{20}$ Based on the CCI score, we defined three comorbidity levels: low (score of 0 ), medium (score of 1-2), and high (score of $3+)$. In addition, we also collected hospital registry data on previous alcoholism-related conditions (yes/no) not included in the CCI and retrieved data on prescriptions for immunosuppressant drugs, including corticosteroids prescribed within 1 year prior to the index date (see Supplementary material for Anatomical Therapeutic Chemical [ATC] codes), as these factors increase the risk of pneumonia. As a proxy for 
socioeconomic status, we used information from the CRS regarding the degree of urbanization (residence in a rural area with a population of $0-10,000$, in a provincial town with a population of $10,000-100,000$, or in a city with more than 100,000 inhabitants). To further control for possible confounding by household living conditions and children as key transmitters of microbial agents, we used the CRS to retrieve data on persons living with small children (younger than 6 years of age [yes/no]).

\section{Statistical analysis}

We used conditional logistic regression to compute crude and adjusted OR as a measure of the incidence rate ratio for pneumonia-related hospitalization according to marital status (married, single, divorced, and widowed), with associated $95 \%$ CI. We adjusted for comorbidities, history of alcoholism-related conditions, previous immunosuppressant use, household presence of small children attending day care centers, and degree of urbanization. To assess the influence of potential mediators on our estimates, we performed sequential cumulative adjustment analysis to estimate whether differences in these mediators accounted for the variation in our results. We further analyzed the data, after stratifying by sex, age-groups, comorbidities, and alcoholism-related conditions.

We externally adjusted for unmeasured confounding by low educational status, based on the knowledge from previous reports that low education doubles the risk of pneumonia, and - in the absence of Danish data - on recent data from the USA that the proportion of married and unmarried individuals with low education is $18 \%$ and $16 \%$, respectively. ${ }^{22-24}$

All analyses were conducted using $\mathrm{SAS}^{\circledR} 9.2$ software (SAS Institute Inc, Cary, NC, USA). The Danish Data Protection Agency approved the study (record number: 2009-41-3866).

\section{Results \\ Descriptive data}

We identified 67,162 patients with incident pneumonia-related hospitalization and 671,620 age-, sex-, and residence-matched population controls. The study population constituted $53 \%$ males, and the median age was 73 years (interquartile range 60-81). Of the 67,162 pneumonia-hospitalized cases, 31,746 (47\%) were married, 8,471 (13\%) were never married, 7,008 (10\%) were divorced, and 19,758 (29\%) were widowed at the index date. Data on marital status was missing for 179 $(<1 \%)$ cases. Compared with their matched population controls, the pneumonia cases were more likely to be never married (12.6\% versus $11.3 \%$ ), and considerably more likely to be divorced (10.4\% versus $7.4 \%$ ) (Table 1$)$. Table 1 also shows the characteristics of cases and controls, stratified by exposure (marital status). Widowed individuals were more likely to be females and older than 80 years, whereas nevermarried individuals were more likely to be younger than 40 years. Divorced persons were more likely to have previous chronic pulmonary disease and alcoholism-related conditions compared with the individuals in the other marital-status exposure groups (Table 1).

\section{Risk estimates}

Table 2 summarizes the analyses of the impact of marital status on the risk of hospitalization with pneumonia. As seen from the age- and sex-matched risk estimates, being never married, divorced, or widowed was associated with substantially increased risk of pneumonia hospitalization. The unadjusted OR for pneumonia hospitalization was 1.30 (95\% CI: 1.26-1.34), 1.59 (95\% CI: 1.54-1.63), and 1.22 (95\% CI: 1.20-1.25) for never-married, divorced, and widowed patients, respectively, compared with patients who were married. After adjusting for the comorbidities listed in the CCI, alcoholism-related conditions, living with small children, degree of urbanization, and immunosuppressant use, the association remained significant, with adjusted ORs of 1.33 (95\% CI: 1.29-1.37) for never-married individuals, 1.29 (95\% CI: 1.25-1.33) for divorced, and 1.15 (95\% CI: 1.12-1.17) for widowed individuals (Table 2).

Controlling for comorbidities only reduced the OR from 1.59 (95\% CI: $1.54-1.63)$ to 1.40 (95\% CI: $1.36-1.44)$ in divorced individuals but yielded no change in the nevermarried group. After controlling for alcoholism-related conditions only, the OR was reduced from $1.30(95 \%$ CI: $1.26-1.33$ ) to 1.23 (95\% CI: 1.19-1.26) for never-married individuals and from 1.59 (95\% CI: $1.54-1.63)$ to $1.43(95 \%$ CI: 1.39-1.74) in divorced individuals (Table 3). When controlling for both alcoholism-related conditions and other comorbidities together in the model, the OR reduced substantially in both divorced (OR: 1.32, 95\% CI: 1.28-1.36) and never-married patients (OR: 1.25, 95\% CI: 1.21-1.29). Thus, alcoholism-related conditions alone appeared to explain approximately $25 \%$ of the association between divorced and never-married status and increased risk of pneumonia.

Table 4 presents the stratified multivariable adjusted ORs for marital status, according to age groups, sex, comorbidity level, and alcoholism-related conditions. The association between never-married status and increased pneumonia-related hospitalization risk was clearly stronger in 


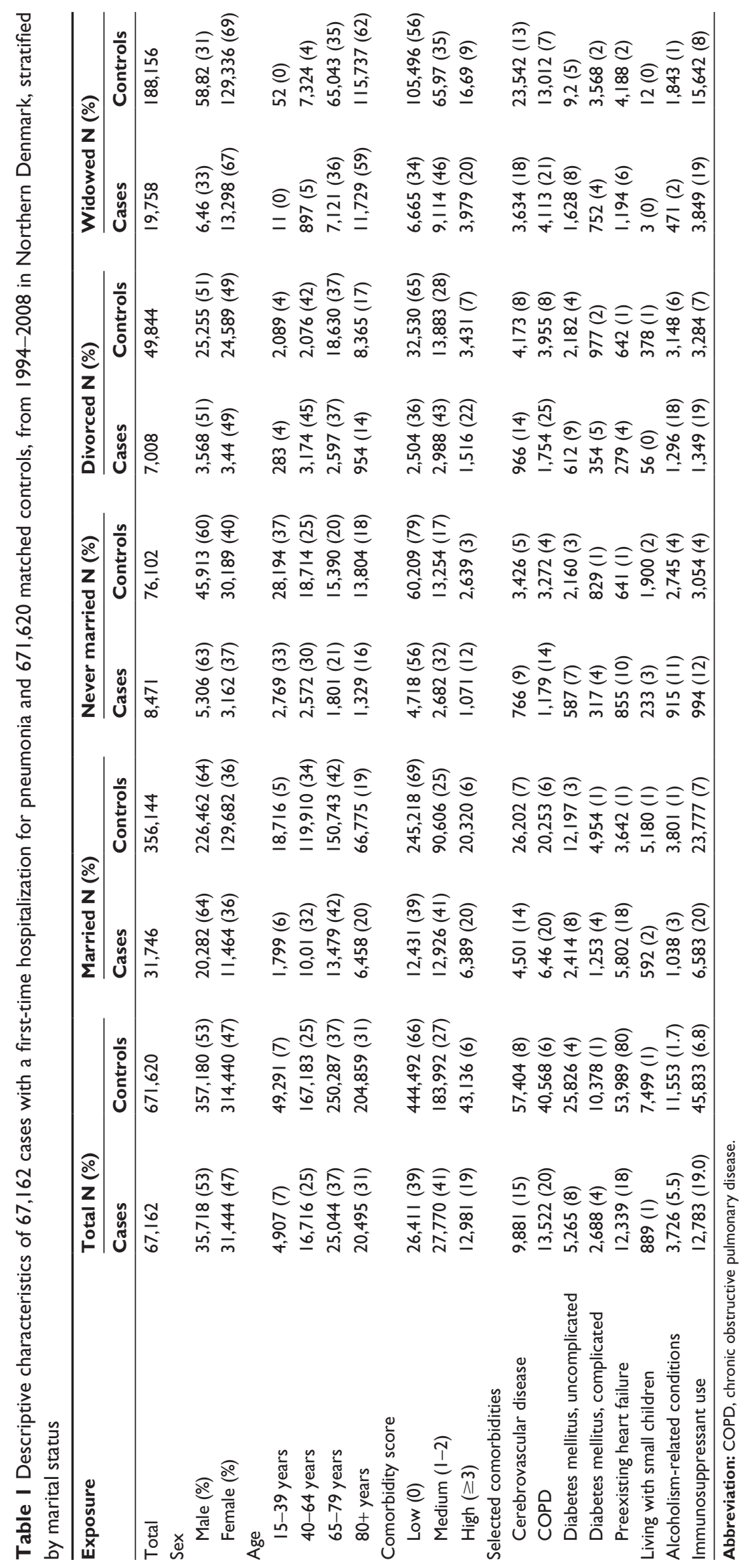


Table 2 Adjusted odds ratios for pneumonia hospitalization associated with marital status

\begin{tabular}{|c|c|c|c|c|}
\hline Exposure & $\begin{array}{l}\text { Cases } \\
\mathbf{N}(\%)\end{array}$ & $\begin{array}{l}\text { Population controls } \\
\text { N (\%) }\end{array}$ & $\begin{array}{l}\text { Unadjusted } \\
\text { OR }(95 \% \mathrm{Cl})\end{array}$ & $\begin{array}{l}\text { Adjusted } \\
\text { OR }^{\mathrm{a}}(95 \% \mathrm{Cl})\end{array}$ \\
\hline Married & $31,746(47.3)$ & $356,144(53.0)$ & $\mathrm{I} .00$ (ref) & $\mathrm{I} .00$ (ref) \\
\hline Never married & $8,47 \mid(\mid 2.6)$ & $76,102(11.3)$ & $1.30(1.26-1.33)$ & $1.33(1.29-1.37)$ \\
\hline Divorced & 7,008 (10.4) & 49,844 (7.4) & $1.59(1.54-1.63)$ & $1.29(1.25-1.33)$ \\
\hline Widowed & $19,758(29.4)$ & $188,156(28.0)$ & $1.22(1.20-1.25)$ & $1.15(1.12-1.17)$ \\
\hline Unknown & $179(0.3)$ & $\mathrm{I}, 374(0.2)$ & $1.48(1.27-1.73)$ & $1.64(1.39-1.93)$ \\
\hline
\end{tabular}

Note: a ${ }^{\circ}$ s adjusted for comorbidities, alcoholism-related conditions, use of immunosuppressant before index hospitalization, household presence of small children, and degree of urbanization.

Abbreviations: $\mathrm{Cl}$, confidence interval; OR, odds ratio; ref, reference.

men (OR: $1.35,95 \%$ CI: 1.30-1.40) than women (OR: 1.21, 95\% CI: 1.16-1.27), whereas the sex differences were small for divorced or widowed people. For all exposure groups, the apparent harmful effect on pneumonia risk decreased both with higher age, and with increasing comorbidity.

The external adjustment for possible unmeasured confounding by low educational level reduced the crude OR from 1.30 to 1.24 .

\section{Discussion}

This large population-based study of more than 67,000 patients with first-time pneumonia-related hospitalization provides evidence that never-married, divorced, and widowed individuals have an increased risk of hospitalization with pneumonia compared with married individuals, the effect being most pronounced in divorced people. We found that alcoholism-related conditions and other comorbidities seem to explain much of the increased pneumonia hospitalization risk in divorced and never-married individuals.

There is limited evidence to compare with the results of our population-based study of pneumonia hospitalization risk, as most previous pneumonia-related studies have focused only on the prognostic effect of marital status. However, in a small case-control study, Farr et al identified single marital status as an independent risk factor for pneumonia (OR: 1.74, 95\% CI: 1.19-2.54) which is consistent with the results of the present study. ${ }^{14}$ Seymour et al found, in the
USA, increased risk for sepsis-related hospitalization among singles (incidence rate ratio [IRR]: 3.5, 95\% CI: 3.1-3.9), widowed (IRR: 1.4, 95\% CI: 1.2-1.6), and divorced (IRR: $1.5,95 \%$ CI: $1.2-1.8)$ compared with married patients, which is consistent with our findings, as pneumonia is a major risk factor for being hospitalized with sepsis. ${ }^{25} \mathrm{~A}$ recent Danish nationwide cohort study of population mortality found increased risk of death due to respiratory tract diseases, including pneumonia, in never-married, widowed, and divorced men (hazard ratios [HRs] between 1.60-2.00) and women (HRs between 1.63-1.79), as compared with married individuals. ${ }^{12}$ Finally, Yu et $\mathrm{al}^{26}$ and Metersky et $\mathrm{al}^{27}$ reported increased mortality in patients hospitalized with cancer or pneumonia who were unmarried, possibly explained by lower socioeconomic status and delayed hospitalization. Supporting this explanation, a recent Danish study reported a highly increased risk of community-acquired bacteremia in individuals with low socioeconomic status. ${ }^{28}$

There are several possible mechanisms behind an association of marriage with decreased risk of pneumonia hospitalization. First, the Health Selection hypothesis suggests that healthy individuals are selected for marriage. ${ }^{29}$ In accordance, we observed a rather high prevalence of comorbidity and especially, alcoholism-related conditions in never-married individuals, in particular when considering that these individuals were much younger on an average compared with married individuals.

Table 3 Odds ratios for pneumonia hospitalization associated with marital status, adjusted individually for selected important variables

\begin{tabular}{|c|c|c|c|c|}
\hline Variables & $\begin{array}{l}\text { Married } \\
\text { OR }(95 \% \mathrm{CI})\end{array}$ & $\begin{array}{l}\text { Never married } \\
\text { OR }(95 \% \mathrm{CI})\end{array}$ & $\begin{array}{l}\text { Divorced } \\
\text { OR }(95 \% \mathrm{CI})\end{array}$ & $\begin{array}{l}\text { Widowed } \\
\text { OR }(95 \% \mathrm{CI})\end{array}$ \\
\hline Unadjusted OR & 1.00 (ref) & $\mathrm{I} .30(\mathrm{I} .26-\mathrm{I} .33)$ & $1.59(1.54-1.63)$ & $1.22(1.20-1.25)$ \\
\hline \multicolumn{5}{|l|}{ OR adjusted for: } \\
\hline Comorbidity index & $\mathrm{I} .00$ (ref) & I.3। (I.27-I.35) & $\mathrm{I} .40(\mathrm{I} .36-\mathrm{I} .44)$ & $\mathrm{I} .17(1.14-1.20)$ \\
\hline Alcoholism-related conditions & $\mathrm{I} .00$ (ref) & $1.23(1.19-1.26)$ & $\mathrm{I} .43$ (I.39-I.47) & $1.19(1.17-1.22)$ \\
\hline COPD & 1.00 (ref) & $1.30(1.26-1.34)$ & $\mathrm{I} .48(\mathrm{I} .44-\mathrm{I} .52)$ & $1.19(1.17-1.22)$ \\
\hline Immunosuppressant use & $\mathrm{I} .00$ (ref) & $1.36(1.30-1.37)$ & I.54 (I.49-I.58) & $1.21(1.18-1.24)$ \\
\hline
\end{tabular}

Abbreviations: $\mathrm{Cl}$, confidence interval; COPD, chronic obstructive pulmonary disease; OR, odds ratio; ref, reference. 
Table 4 Association between marital status and pneumonia hospitalization, stratified by sex, age and comorbidity

\begin{tabular}{|c|c|c|c|c|}
\hline & $\begin{array}{l}\text { Married } \\
\text { Adjusted } \\
\text { OR }^{\mathrm{a}}(95 \% \mathrm{Cl})\end{array}$ & $\begin{array}{l}\text { Never married } \\
\text { Adjusted } \\
\text { OR }^{\text {a }}(95 \% \mathrm{Cl})\end{array}$ & $\begin{array}{l}\text { Divorced } \\
\text { Adjusted } \\
\text { OR }^{\mathrm{a}}(95 \% \mathrm{CI})\end{array}$ & $\begin{array}{l}\text { Widowed } \\
\text { Adjusted } \\
\text { OR }^{\mathrm{a}}(95 \% \mathrm{Cl})\end{array}$ \\
\hline \multicolumn{5}{|l|}{ Sex } \\
\hline Male & $\mathrm{I} .00$ (ref) & $1.35(1.30-1.40)$ & $1.58(1.52-1.64)$ & $1.24(1.20-1.28)$ \\
\hline Female & 1.00 (ref) & $1.21(1.16-1.27)$ & $1.59(1.53-1.66)$ & $1.21(1.17-1.25)$ \\
\hline \multicolumn{5}{|l|}{ Age group in years } \\
\hline $15-39$ & 1.00 (ref) & $1.00(0.93-1.08)$ & $1.41(1.23-1.61)$ & $2.20(1.14-4.24)$ \\
\hline $40-64$ & 1.00 (ref) & $1.67(1.59-1.75)$ & $1.83(1.75-1.91)$ & $1.46(1.36-1.57)$ \\
\hline $65-79$ & 1.00 (ref) & $1.32(1.25-1.39)$ & $1.57(1.50-1.64)$ & $1.26(1.22-1.30)$ \\
\hline $80+$ & 1.00 (ref) & $1.00(0.94-1.07)$ & $1.18(1.10-1.27)$ & $1.06(1.02-1.10)$ \\
\hline \multicolumn{5}{|l|}{ Comorbidity level } \\
\hline Low & $\mathrm{I} .00$ (ref) & $1.34(1.28-1.40)$ & $1.52(1.45-1.60)$ & $1.22(1.17-1.27)$ \\
\hline Medium & 1.00 (ref) & $1.25(1.18-1.33)$ & $1.35(1.28-1.42)$ & $1.15(1.11-1.20)$ \\
\hline High & 1.00 (ref) & $0.94(0.82-1.09)$ & $1.07(0.95-1.2 \mathrm{I})$ & $1.04(0.96-1.13)$ \\
\hline COPD & 1.00 (ref) & $1.08(0.93-1.24)$ & $1.25(1.12-1.40)$ & $1.13(1.04-1.23)$ \\
\hline Alcoholism-related conditions & 1.00 (ref) & $1.40(1.09-1.79)$ & $1.40(1.11-1.77)$ & $1.76(1.15-2.70)$ \\
\hline Immunosuppressant use & $\mathrm{I} .00$ (ref) & $1.25(1.08-1.44)$ & $1.47(1.30-1.65)$ & $1.20(1.10-1.30)$ \\
\hline
\end{tabular}

Second, the 'social causation hypothesis' argues that marriage in itself has a protective effect against diseases, through higher socioeconomic security, healthier lifestyle, and higher degree of social integration. ${ }^{30,31}$ We found that the association between being unmarried and risk of pneumonia-related hospitalization was stronger in men than in women, and lack of marriage may be a risk factor for unhealthy choices. Corroborating this, Eng et al, ${ }^{32}$ in a study of 38,865 men, found an association between divorced or widowed status and decreased intake of vegetables ( 2.05 and 2.91 servings/week in divorced and widowed men, respectively), decreased body mass index $\left(-0.31\right.$ and $-0.35 \mathrm{~kg} / \mathrm{m}^{2}$ in divorced and widowed men, respectively), increased alcohol intake $(+0.51$ servings of alcohol per week in widowed men), and increased cigarette consumption $(+0.32$ cigarettes per day in divorced men) as compared with men who were married. ${ }^{32}$ Our finding that alcoholism-related conditions along with comorbidities explained much of the increased risk of pneumonia in divorced and widowed individuals is consistent with this hypothesis, although our data did not allow us to disentangle the exact time order of marriage, divorce, and lifestyle-related comorbidity. We also found increased prevalence of in particular, COPD (a surrogate measure for smoking) among divorced individuals, which may be due to the occurrence of divorced individuals indulging in unhealthy behaviors or smokers getting divorced more often. Both tobacco smoking and alcohol overuse are wellestablished risk factors for pneumonia. ${ }^{33}$ Unfortunately, we lacked the necessary lifestyle factor data to investigate these hypotheses further.

Finally, spouses may exert possible benefits, either by functioning as home health assistants or by functioning as higher-order decision makers ${ }^{34}$ encouraging their spouses to seek early medical attention and antibiotic treatment, both potentially leading to avoidance of hospitalization with pneumonia. On the other hand, spouses may advocate hospital versus home treatment of the patient, potentially leading to less severe pneumonia cases being hospitalized. In line with this, Metersky et al found that married individuals with hospitalized pneumonia were less likely to require intensive care admission or mechanical ventilation than unmarried individuals, pointing toward decreased severity of pneumonia at the time of hospitalization. ${ }^{27}$

The strengths of our study include its large size, population-based design, and adjustment for several important confounders, made possible through access to medical databases providing a complete medical and prescription history. Despite inevitable coding errors in clinical practice, the estimated predictive value of a diagnosis of pneumonia in Denmark is $90 \%{ }^{3}$ The main limitations include potential un- and undermeasured confounding, lack of history of marital status, and misclassification. The role of tobacco smoking and alcohol overuse, well-established risk factors for pneumonia, ${ }^{33}$ was possibly only partially removed by controlling for COPD and alcohol-related disorders. We did not have access to data on employment or household income, 
but adjustment for urbanization, number of children, and external adjustment for educational status may have removed some possible confounding by socioeconomic status. We used data on educational level from marital status from the USA. Even when considering both the USA and Denmark as developed western countries with high educational level, there may still be some differences in the educational level between these countries, according to the marital status. Lack of data on important lifestyle factors and other pneumonia predictors, such as immunizations, additionally may have hampered our ability to further investigate the mechanisms behind the association between marital status and pneumonia. Furthermore, marriage may have a cumulative effect, and not considering the history and transition of marital status may have hampered our results. ${ }^{29} \mathrm{We}$ only had information of marital status at the time of hospitalization and since our dataset lacked details about the transitions of marital status, we could not further elucidate their effects. For example, the rather low risk estimate for the widowed group observed in our study might point toward a cumulative effect of previous marriage. Finally, in Denmark, it is rather frequent to live together with a partner on a long-term basis without being married (cohabitation). ${ }^{12}$ This misclassification of exposure may have diluted our risk estimate for the never-married group, and the true pneumonia risk associated with living without a partner might be even stronger than predicted.

\section{Conclusion}

In conclusion, our data, combined with previous results, provide evidence that single marital status is associated with an increased risk of pneumonia hospitalization. The present study highlights the need to elucidate the underlying mechanisms that link marital status to pneumonia hospitalization risk, focusing on socioeconomic factors, including education and personal income, and lifestyle factors, including health consciousness, healthy choices, and access to health care.

\section{Disclosure}

The authors report no conflicts of interest in this work.

\section{References}

1. Fry AM, Shay DK, Holman RC, Curns AT, Anderson LJ. Trends in hospitalizations for pneumonia among persons aged 65 years or older in the United States, 1988-2002. JAMA. 2005;294(21):2712-2719.

2. Trotter CL, Stuart JM, George R, Miller E. Increasing hospital admissions for pneumonia, England. Emerging Infect Dis. 2008;14(5):727-733.

3. Thomsen RW, Riis A, Nørgaard M, et al. Rising incidence and persistently high mortality of hospitalized pneumonia: a 10-year population-based study in Denmark. J Intern Med. 2006;259(4):410-417.
4. Centers for Disease Control and Prevention (CDC). Bacterial coinfections in lung tissue specimens from fatal cases of 2009 pandemic influenza A (H1N1) - United States, May-August 2009. MMWR Morb Mortal Wkly Rep. 2009;58(38):1071-1074.

5. Aliberti S, Blasi F. The management of patients with communityacquired pneumonia beyond antibiotic therapy. Eur J Intern Med. 2012;23(5):389-390.

6. Christensen S, Jacobsen J, Bartels P, Nørgaard M. [Hospital standardised mortality ratios based on data from administrative registries. A pilot project]. Ugeskr Laeg. 2007;169(34):2767-2772. Danish.

7. Johnson NJ, Backlund E, Sorlie PD, Loveless CA. Marital status and mortality: the national longitudinal mortality study. Ann Epidemiol. 2000;10(4):224-238.

8. Osborne C, Ostir GV, Du X, Peek MK, Goodwin JS. The influence of marital status on the stage at diagnosis, treatment, and survival of older women with breast cancer. Breast Cancer Res Treat. 2005;93(1):41-47.

9. Manzoli L, Villari P, M Pirone G, Boccia A. Marital status and mortality in the elderly: a systematic review and meta-analysis. Soc Sci Med. 2007;64(1):77-94.

10. Dupre ME, Beck AN, Meadows SO. Marital trajectories and mortality among US adults. Am J Epidemiol. 2009;170(5):546-555.

11. Rosengren A, Wedel H, Wilhelmsen L. Marital status and mortality in middle-aged Swedish men. Am J Epidemiol. 1989;129(1):54-64.

12. Frisch M, Simonsen J. Marriage, cohabitation and mortality in Denmark: national cohort study of 6.5 million persons followed for up to three decades (1982-2011). Int J Epidemiol. 2013;42(2):559-578.

13. Gove WR. Sex, marital status, and mortality. AJS. 1973;79(1):45-67.

14. Farr BM, Bartlett CL, Wadsworth J, Miller DL. Risk factors for community-acquired pneumonia diagnosed upon hospital admission. British Thoracic Society Pneumonia Study Group. Respir Med. 2000;94(10):954-963.

15. Ministeriet for Sundhed og Forebyggelse [Ministry of Health and Prevention]. Health Care in Denmark. Copenhagen: Ministeriet for Sundhed og Forebyggelse; 2008. Available from: http://www.sum. $\mathrm{dk} /$ Aktuelt/Publikationer/Publikationer/UK_Healthcare_in_DK.aspx. Accessed July 15, 2013.

16. Pedersen CB. The Danish Civil Registration System. Scand J Public Health. 2011;39(Supp1 7):S22-S25.

17. Lynge E, Sandegaard JL, Rebolj M. The Danish National Patient Register. Scand J Public Health. 2011;39(Supp1 7):S30-S33.

18. Wacholder S, Silverman DT, McLaughlin JK, Mandel JS. Selection of controls in case-control studies. III. Design options. Am J Epidemiol. 1992;135(9):1042-1050.

19. Kildemoes HW, Sørensen HT, Hallas J. The Danish National Prescription Registry. Scand J Public Health. 2011;39(Suppl 7):S38-S41.

20. Thomsen RW, Hundborg HH, Lervang HH, Johnsen SP, Schønheyder HC, Sørensen HT. Risk of community-acquired pneumococcal bacteremia in patients with diabetes: a population-based case-control study. Diabetes Care. 2004;27(5):1143-1147.

21. Charlson ME, Pompei P, Ales KL, MacKenzie CR. A new method of classifying prognostic comorbidity in longitudinal studies: development and validation. J Chronic Dis. 1987;40(5):373-383.

22. Lash TL, Fink AK. Semi-automated sensitivity analysis to assess systematic errors in observational data. Epidemiology. 2003;14(4):451-458.

23. Empana JP, Jouven X, Lemaitre R, et al. Marital status and risk of outof-hospital sudden cardiac arrest in the population. Eur J Cardiovasc Prev Rehabil. 2008;15(5):577-582.

24. Jasti H, Mortensen EM, Obrosky DS, Kapoor WN, Fine MJ. Causes and risk factors for rehospitalization of patients hospitalized with community-acquired pneumonia. Clin Infect Dis. 2008;46(4):550-556.

25. Seymour CW, Iwashyna TJ, Cooke CR, Hough CL, Martin GS. Marital status and the epidemiology and outcomes of sepsis. Chest. 2010;137(6): 1289-1296.

26. Yu GP, Mehta V, Branovan D, Huang Q, Schantz SP. Non-cancerrelated deaths from suicide, cardiovascular disease, and pneumonia in patients with oral cavity and oropharyngeal squamous carcinoma. Arch Otolaryngol Head Neck Surg. 2012;138(1):25-32. 
27. Metersky ML, Fine MJ, Mortensen EM. The effect of marital status on the presentation and outcomes of elderly male veterans hospitalized for pneumonia. Chest. 2012;142(4):982-987.

28. Koch K, Søgaard M, Nørgaard M, Thomsen RW, Schønheyder HC; for the Danish Collaborative Bacteraemia Network (DACOBAN). Socioeconomic inequalities in risk of hospitalisation with communityacquired bacteraemia: a Danish population-based case-control study. Poster presented at the 23rd ESCMID conference; April 27-30; 2013; Berlin.

29. Lund R, Holstein BE, Osler M. Marital history from age 15 to 40 years and subsequent 10-year mortality: a longitudinal study of Danish males born in 1953. Int J Epidemiol. 2004;33(2):389-397.

30. Joung IM, van de Mheen H, Stronks K, van Poppel FW, Mackenbach JP. Differences in self-reported morbidity by marital status and by living arrangement. Int J Epidemiol. 1994;23(1):91-97.
31. Goldman N. Marriage selection and mortality patterns: inferences and fallacies. Demography. 1993;30(2):189-208.

32. Eng PM, Kawachi I, Fitzmaurice G, Rimm EB. Effects of marital transitions on changes in dietary and other health behaviours in US male health professionals. J Epidemiol Community Health. 2005;59(1): $56-62$.

33. Kornum JB, Due KM, Nørgaard M, et al. Alcohol drinking and risk of subsequent hospitalisation with pneumonia. Eur Respir J. 2012;39(1): 149-155.

34. Iwashyna TJ, Christakis NA. Marriage, widowhood, and health-care use. Soc Sci Med. 2003;57(11):2137-2147. 


\section{Supplementary material}

World Health Organization International Classification of Diseases (ICD)-10 codes and Anatomical Therapeutic Chemical classification system (ATC) $\operatorname{codes}^{1}$ used in this study:

\section{Pneumonia}

J12-J18, A481 and A709

\section{Alcoholism-related disorders}

F10, K86.0, Z72.1, R78.0, T51

\section{Systemic antibiotics}

ATC code: J01.

\section{Immunosuppressive drugs}

ATC codes: L01, L04, and H02AB

\section{Reference}

1. World Health Organization. Guidelines for ATC classification and DDD assignment. Oslo: WHO Collaborating Centre for Drug Statistics Methodology; 2013. Available from: http://www.whocc.no/atc_ddd_index/. Accessed September 4, 2013.

\section{Publish your work in this journal}

Clinical Epidemiology is an international, peer-reviewed, open access journal focusing on disease and drug epidemiology, identification of risk factors and screening procedures to develop optimal preventative initiatives and programs. Specific topics include: diagnosis, prognosis, treatment, screening, prevention, risk factor modification, systematic

Submit your manuscript here: http://www.dovepress.com/clinical-epidemiology-journal

\section{Dovepress}

reviews, risk \& safety of medical interventions, epidemiology \& biostatical methods, evaluation of guidelines, translational medicine, health policies \& economic evaluations. The manuscript management system is completely online and includes a very quick and fair peer-review system, which is all easy to use. 